\title{
ANTONIO SAMUDIO
}

\author{
Juan Gustavo Cobo Borda (Colombia)
}

coboborda@yahoo.com

\section{Resumen:}

Juan Gustavo Cobo Borda presenta un análisis de la obra del artista bogotano Antonio Samudio. Explora sus temas, motivaciones y describe, desde su punto de vista, el mundo sórdido y misterioso al que invitan las pinturas de Samudio.

Palabras clave: Expresionismo, artistas colombianos, pintura colombiana, Antonio Samudio.

\section{Abstract:}

Juan Gustavo Cobo Borda presents an analysis of the work of bogotan artist Antonio Samudio. Cobo explores his themes, motives and describes, from his point of view, the sordid, mysterious world which Samudio's paintings invite to.

Keywords: Expresionism, colombian artists, colombian painting, Antonio Samudio. 


\title{
ANTONIO SAMUDIO
}

\begin{abstract}
Reseña de autor:
Juan Gustavo Cobo Borda (Colombia)

Poeta y ensayista bogotano. Fue director durante una década (1973-1984) de la revista

Eco, de la librería Buchholz, y Gaceta, del Instituto Colombiano de Cultura. Ha ocupado

cargos diplomáticos en Buenos Aires y Madrid y fue embajador en Grecia. Miembro número de la Academia Colombiana de la Lengua desde 1993, y correspondiente, de la Academia Española. Ha sido jurado tres veces del Premio Juan Rulfo, (Guadalajara, México); del Rómulo Gallegos, (Caracas); del Reina Sofía de poesía iberoamericana

(Madrid) y del Neustad, Universidad de Oklahoma, Estados Unidos. Ha colaborado con otras publicaciones, como Plural, de México, ABC, de España, y El Nacional de Venezuela. Entre sus poemarios figuran Consejos para sobrevivir (1974); Todos los poetas son santos

(1987); Dibujos hechos al azar de lugares que cruzaron mis ojos (1991) y La musa inclemente (2001), entre otros. Algunas de sus publicaciones son Lengua Erótica: antología poética para hacer el amor (Villegas Editores, 2004), Lector impenitente, El olvidado arte de leer, Enclave de palabras número tres Acosado animal (Politécnico Grancolombiano, 2010),

Vargas Llosa: La pasión de narrar (Alfaguara, 2010), sus más recientes publicaciones.
\end{abstract}

El pequeño teatro de cámara que es la obra de Antonio Samudio (Bogotá, 1935) basa su encanto en lo no dicho, en el secreto atisbado pero a la vez sugerente en su camuflada insinuación. Porque aquello que lo obsesiona no es lo sexual explicito sino el largo, tortuoso y fascinante camino de la seducción. Sea la proverbial manzana, fruto prohibido, o también la espera que carga la tensión en diálogos imposibles, pues hombres y mujeres, en su obra, brindan siempre una atónita rigidez, una impávida mirada, que tiene tanto de máscara como de picardía desviada: miran lo que no toca. Anverso y reverso de la zona prohibida, como en muchos de sus bodegones, columpios, o salas de visitas porque siempre allí los muslos se ofrecen con recatada impudicia, con sospechosa formalidad de cuello rígido y corbata fina, mientras el femenino pie descalzo, bajo la mesa, provoca e interroga. 
Todos estos interiores sosegados y burgueses ven su atmósfera claustral acentuada por el pequeño formato que utiliza, con una prodigalidad de senos y posturas, de sexos y ropa intima que nos pasean de la risa al desconcierto, de deleites pecaminosos del voyerismo al tranquilo exhibicionismo de quien se tiende $y$ ofrece sea como "Jugo de manzanas", óleo de 2007, o "En bandeja", óleo de 2010. El hombrecito de largas patillas, trasunto del mismo Samudio, se ve enfrentado al mayor desafío. Lo que soñó, ansió y persiguió el fantasma imposible esta ahora allí; acostado, con su bosque y sus colinas, y el perverso pintor lo ha condenado a ser solo pintura. Cruce de miradas, en el cuadrilátero de los ojos que se proyectan, ávido el, indiferente ella.

Todos ellos congelados cual tira dibujada por un adolescente morboso, cual postal clandestina ocultada en un libro. Porque Samudio no ha vacilado en ilustrar a los mas ascéticos y complejos, llámense César Vallejo, llámense Juan Rulfo, como quien se entrena en la sequedad desértica de la palabra para tornar luego a la poesía inmóvil de los erosionados objetos de Morandi, de la riqueza de los collages de Braque o de un guiño, muy suyo, al Picasso. Las señoritas, de Samudio, tan formales bien pueden colarse en un burdel y ofrecer sus ancas al mejor postor, o seguir allí, haciendo fila o manipulando frutas, cafeteras o tinas, donde todo parece retozar en una estrechez un tanto agobiada porque en verdad este mundo de sensuales protagonistas es también un espacio claustrofóbico donde los ojos se esconden detrás de lienzos atónitos, ventanas que no se abren sino se entornan, o cerraduras que apenas si permiten imaginar escenas tórridas, mas propias de la imaginación que de la estrecha rendija con que nos asomamos al culpable atisbo.

Otros enfoques de Samudio trabajan mas bien con una gimnasia erótica tan pueril como circense, trepándose a los árboles o instalándose en las cabezas de sus protagonistas que reciben ese deleitoso trofeo con la habitual parsimonia con que toda la escenografía de Samudio tiene ese aire desapegado de oscuros fondos mates y recreaciones clásicas, en desnudos, arboles y cortinas que enmarcan pero también mantienen el secreto de esta pintura que al retomar los mismos elementos los torna mas inquietantes y mas complejos y gratificantes. 


\section{Antonio Samudio (Bogotá, 1934)}

Pintor y grabador, ha sido incluido por la crítica en el grupo Expresionista Colombiano, al cual pertenecen Ángel Loochkartt, Leonel Góngora y Carlos Granada; a pesar de que en su obra, no existe la tragedia ni la referencia a una realidad desgarradora. Estudió en la Facultad de Bellas Artes Universidad Nacional. En 1966 colgó su primera exposición en la Galería Arte Moderno de Bogotá. En 1968 viajó a Caracas donde presentó su obra en la Galería El Muro. En 1974 expuso en el salón Siglo XX de Quito, Ecuador. En 1977 en la Galería Arte Autopista de Medellín. En 1989 presentó su trabajo en la Galería Belarca y en 1990 un conjunto de sus grabados fueron exhibidos en el Museo Rayo de Roldanillo. Su obra se ha caracterizado por su indagación en el humor y es notorio el refinamiento en el uso de colores pasteles. Ha publicado los libros: Libraco de Grabados (1986), Tríptico de Comala (1986), País en Mezzotinta (1996), Teatro de Sombras con Cesar Vallejo (2002) y Cuadros de una exposición (2002). Tomado de: http://www.pintores-colombianos. blogspot.com/

\section{Currículum de exposiciones}

\section{Premios}

1961. II Premio en Grabado "Salón Cano” (Bellas Artes Bogotá).

1961. II Premio en Pintura "Salón Cano” (Bellas Artes Bogotá).

1962. I Premio en Grabado "Salón Nacional" (Cúcuta).

1962. I Premio en Pintura "Salón de Estudiantes de Arte” (Cali).

1965. II Premio, "Segundo Salón de Pintura Croydon" (Cali).

1966. III Premio, “Tercer Salón de Pintura Croydon" (Cali).

1971. I Premio Pintura, VI Salón de Agosto, Museo de Arte Contemporáneo, Bogotá.

1965. I Premio de Pintura "Sociedad Amigos del Arte" (Sta Marta).

1973. II Premio "Bienal Latinoamericana Sugamuxi” (Sogamoso).

1976. I Premio, X Salón Internacional de Agosto, Museo de Arte Contemporáneo, Bogotá. 


\section{Reconocimientos}

1966. Primera Mención, "Concurso

Estampilla de la Productividad”.

1971. Tarjeta de Oro "Gran Reconocimiento V Salón de Agosto”.

1976. Gran Reconocimiento Internacional X Salón de Agosto. Museo de Arte Contemporáneo de Bogotá.

\section{Representado en:}

Colecciones públicas:

Museo de Arte Contemporáneo, Bogotá.

Colección “Coltejer”. Medellín.

Biblioteca Pública Piloto de Medellín, Colombia.

Biblioteca Luis Ángel Arango, Bogotá.

Museo de Bellas Artes, Caracas.

\section{Colecciones privadas de:}

Colombia, Venezuela, Estados Unidos, España, Francia, Alemania, Holanda, Inglaterra, Japón, Ecuador, Perú, Chile, Argentina, México, Cuba, entre otras.

\section{Exposiciones individuales}

1967. Galería “Arte Moderno” Bogotá.

1971. Galería "Arte Moderno" Bogotá.

1973. Centro “Coltejer" Medellín.

1974. Galería Siglo XX Quito Ecuador.

1975. Galería San Diego. Bogotá.

1975. Galería Ivonne Briceño. Lima - Perú.

1976. Galería Arvil. México.

1977. Galería Arte Autopista. Medellín.

1979. Galería Arte Autopista. Medellín.

1982. Galería Arte Autopista. Medellín.

1986. Galería Arte Autopista. Medellín.

1986. Lanzamiento del Libro "Libraco con Grabados".

1986. Galería Sextante. Bogotá.

1986. Biblioteca Pública Piloto. Medellín.

1987. Galería Manzana Verde. Quito - Ecuador. 
1989. Galería Belarca. Bogotá.

1990. Museo Rayo, "Grabados", Roldadillo, Valle-Colombia.

1993. Galería Arteria, Barranquilla - Colombia.

1995. Quinta Galería. "La Ironía del Sarcasmo". Bogotá.

1995. Galería Sextante, Gráfica y Dibujos, Bogotá.

1996. Galería Sextante. "País en Mezzotinta”. Bogotá.

1997. Galería Forum. Lima - Perú.

2002. Quinta Galería, "Grafi-Collage”, Bogotá.

2002. Biblioteca Pública Piloto, "El Color del Silencio", Medellín.

2004. Quinta Galería, "Obra Reciente", Bogotá.

2005. Galería Julieta Álvarez, (en el marco del XV Festival Internacional de Poesía de Medellín) Colombia.

2007. Galería Sextante "Pinturas". Bogotá.

2009. Museo Nacional, (Obras de Samudio en el marco de la presentación del libro "Antonio Samudio"- Marzo 12 de 2009).
2010 Galería Sextante "Pinturas o paisajes". Bogotá.

\section{Exposiciones colectivas}

1961. Salón Cano. Bellas Artes, Bogotá.

1962. Salón Nacional de Estudiantes de Arte. Cali.

1962. XIV Salón Nacional de Artistas. Bogotá.

1962. Salón Nacional de Grabado. Cúcuta.

1963. III Festival de Arte. Cali.

1963. Salón "Intercol" de Artistas Jóvenes, Museo de Arte Moderno. Bogotá.

1964. XVI Salón Nacional de Artistas. Bogotá.

1964. I Salón Nacional de Pintura Croydon. Cali.

1965. II Salón Nacional de Pintura Croydon. Cali.

1966. XVIII Salón Nacional de Artistas. Bogotá.

1966. III Salón Nacional de Pintura Croydon. Cali. 
1967. XIX Salón Nacional de Artistas. Bogotá.

1968. I Bienal de Arte Coltejer. Medellín.

1968. VIII Festival de Arte. Cali.

1970. IV Bienal Americana de Grabado. Santiago de Chile.

1970. II Bienal de Arte Coltejer. Medellín.

1971. V Salón de Agosto, Museo de Arte Contemporáneo. Bogotá.

1971. XXII Salón Nacional de Artistas. Bogotá.

1972. VI Salón de Agosto, Museo de Arte Contemporáneo. Bogotá.

1972. III Bienal de Arte Coltejer. Medellín.

1972. Salón Nacional de Artistas, Universidad "Jorge Tadeo Lozano". Bogotá.

1972. Exposición de Miniaturas Galería Nacional. Bogotá.

1973. I Bienal Latinoamericana Sugamuxi. Sogamoso. NO

1975. Cinco Pintores. Artes Galería. Bogotá.
1977. Muestra. I Volumen "Panorama Artístico Colombiano". Galería El Callejón. Bogotá.

1979. Encuentro Iberoamericano de Críticos y Artistas. Museo de Bellas Artes. Caracas.

1979. Muestra. II Volumen "Panorama Artístico Colombiano". Galería El Callejón. Bogotá.

1981. IV Bienal de Arte. Medellín.

1981. Muestra. III Volumen "Panorama Artístico Colombiano". Galería El Callejón. Bogotá.

1983. Muestra. IV Volumen "Panorama Artístico Colombiano”. Galería El Callejón. Bogotá.

1984. Galería Sextante. Homenaje a Pablo Neruda. Bogotá.

1984. Sala de Exposiciones de Suramericana. "Neruda y la alegría del mundo". Bogotá.

1984. Biblioteca Pública Piloto."Tres Aspectos de la Figuración". Medellín.

1984. $X$ Portafolio Internacional de Grabado. Colección Cartón de Colombia S.A. AGPA. Museo de Arte Moderno. Bogotá. 
1984. Cámara de Comercio de Bogotá. "Pintores Generacionales". Bogotá.

1987. Galería La Francia. "Muestra del Desnudo”. Medellín.

1987. Galería Belarca "Sexo y Violencia”, Bogotá.

1988. Galería Elida Lara, Barranquilla.Col.

1988. Biblioteca Luis Ángel Arango, Ex - Libris de Benoit Junot. Bogotá.

1992. Galería El Museo, "Homenaje a Obregón”, Bogotá.
2004. Sala de Exposiciones del Archivo de Bogotá. "El Arte va a la Biblioteca”. Bogotá.

2005 - 2008. Múltiples exposiciones colectivas a nivel nacional e internacional.

2007. CAF (Corporación Andina de Fomento). "Artistas Latinoamericanos en Colecciones Venezolanas". Caracas - Venezuela.

2009. Quinta Galería "Exposición Colectiva”.

2009. Museo Nacional "Artistas Colombianos en la colección Bancafé". 